\title{
3D Reproductions: The replicated object, a speculative model
}

\author{
Christina Karababa \\ University of Applied Sciences, \\ Düsseldorf Institut.Bild.Media, \\ Kaiserswerther Str. 197 \\ 40474 Düsseldorf, Germany \\ info@christina-karababa.com
}

\begin{abstract}
Generating a reproduction as a 3D-object, is a creative process that marks a new status for the object, and consequently, these reproductions enter a relationship of difference with the original object. The model has a physical presence, which is location independent and carries the duplication of the reproduction in itself. This type of object is transportable, location-independent, can be accessed from all over the world, and calls for collective net-empiricism. In this context, a 3D artistic investigation has been developed by using a 3D scan of Peter Weibel, the Director of the Karlsruhe Center for Art and Media (ZKM), which is openly accessible on an online platform. Modifications as well as remixes with other scans, are parts of the work.
\end{abstract}

Generative production methods. 3D models. Open source data.

\section{INTRODUCTION}

We are in the so-called post-digital age, in which digital technologies are an omnipresent and almost invisible phenomenon. Data sets can not only be visualised as projections with, for example, holographic techniques, but can also be materialised as three-dimensional objects manufactured by generative production processes. Therefore, a new type of technological object is emerging, which needs a new definition and interpretation, and we must also decipher the messages that it carries. Creative practice with digital generative production methods is also bringing dynamic new ways of thinking and research via new methodologies.

What form of knowledge generates digital reproducibility and what kind of experience is transported with? Can the experience of materialisation lead to further approaches? Can the three-dimensional object prompt issues for a debate on visual and haptic thinking explorations? Is it possible to find added value through the speculations generated by a 3D-object?

\section{THE REPLICATED OBJECT}

Before the introduction of image printing methods, reproductions existed in the form of copies with certain deviations from one another. It was only after the introduction of the printing method that the term 'reproductions' emerged, thereby shaping our understanding of the relationship between original and the replica to this day. Reproductions served as tools that allowed the circulation of inaccessible unique specimens, and made them accessible or transportable in the form of small format-replicas, graphics or photographs. Due to improved accessibility and changes in media and size, reproductions have arguably informed our visual memory more than the originals (see Figure 1).

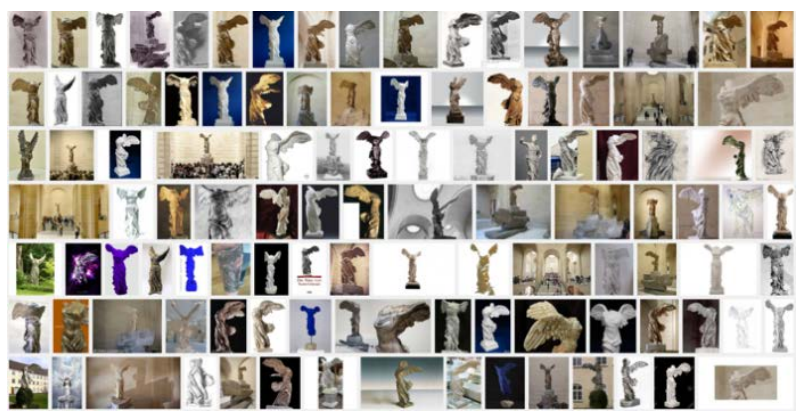

Figure 1: Google search: Nike of Samothrace.

The principle of reproduction intensified common viewing and enabled exchanges and comparisons to take place at different locations. The principle of reproduction gives the viewer the impression that, in principle, everyone sees the same thing, 
regardless of whether one looks at a graphic or a photograph of a sculpture or the original sculpture itself. As a matter of principle, everyone has, materially speaking, the same object in front of their eyes, as similar optical impressions fall onto the retina. The picture everyone sees is basically mass media, cross-cultural and communicable (Frank \& Lange 2010, p.50).

Neither the picture itself, nor its concrete, material implementation, is decisive for perception. It is not only the condition of reception, but also the access options for the corresponding technologies that determines whether these plural images can be seen and by whom (Frank \& Lange 2010, p.52).

Openly accessible online 3D reproductions, in the form of data, renders objects as transportable and available, irrespective of material, production facilities and economic efficiency. These dataobjects can be considered from an interaction of shifting perspectives, and can be printed out in different formats and materials if needs be. They can be examined in detail in various ways, thereby increasing their visibility and their potential for perception and application. Previously, a comprehensive representation of fragile, precious or large objects, which could be accessed from all sides, could not be realised. Through the transfer of physical objects by means of digitisation into virtual space - beyond geographic boundaries - different modes of processing, and methods for investigating numerous research questions can devised, thereby generating new knowledge. Free access to this data opens up many possibilities for the storage and access of objects for a broad spectrum of applications.

Cultural institutions in particular are having their holdings digitally recorded and are making them freely accessible through their archives. Non-profit organisations such as CyArk for example, are cooperating with Google for the Open Heritage project, have digitised various cultural exhibits and buildings using 3D technologies (https://cyark.org/discovery/openheritage). Their 3D data has consequently become freely available online for further research. Other cultural institutions, such as the American Smithsonian Institute based in Washington, D.C., intend to digitise their entire collections, not only for internal purposes such as restorations, but also to display as archives online (https://3d.si.edu).

Cultural assets, such as the Winged Victory of Samothrake (see Figure 2), which have been generated by precise 3D scanning, and which have been publicly available on the Internet portal Thingiverse, thus become transportable, locationindependent and accessible all over the world.
They are models that invite new formations and demand collective net-empiricism (see Figure 3).

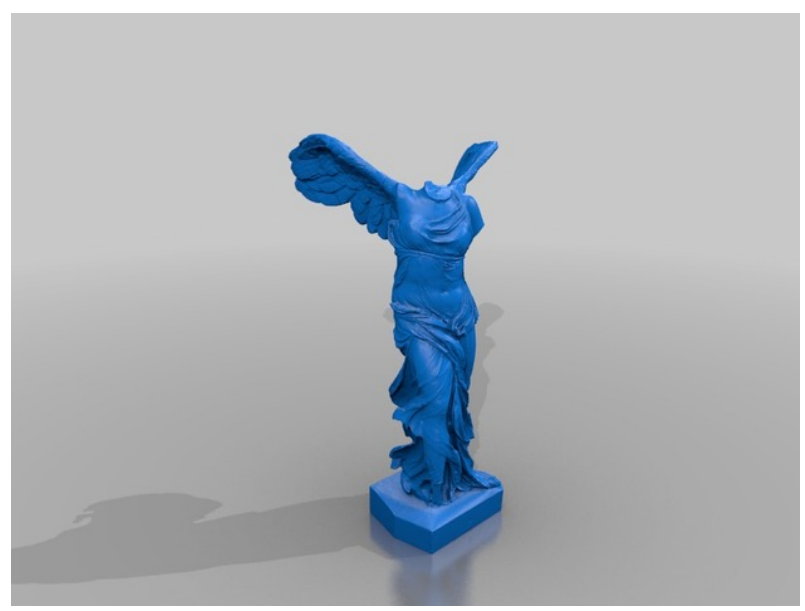

Figure 2: Winged Victory of Samothrake, by CosmoWenman, published 16 December 2013 (www.thingiverse.com/thing:196038). 3D scanning of a reproduction of the Nike from the inventory of the Museum Skulpturhalle Basel.

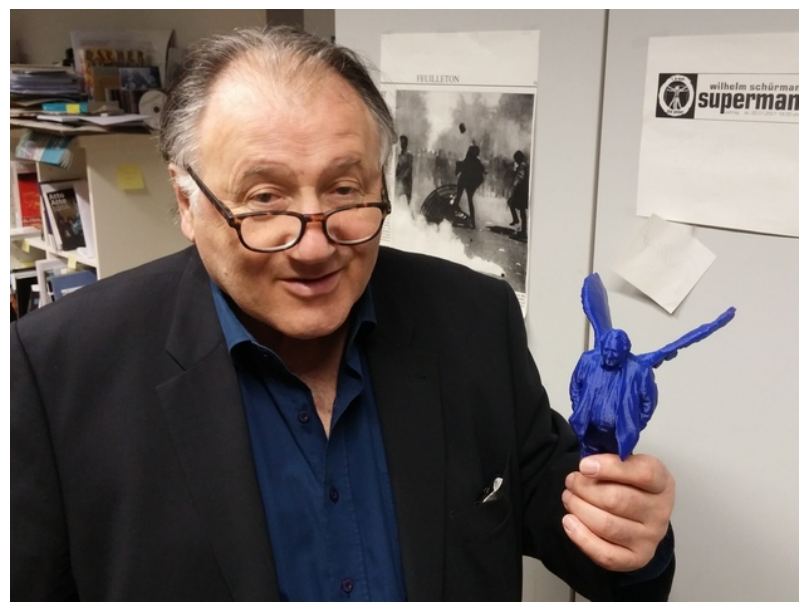

Figure 3: Peter Weibel with 3D-Model Peter Weibel and I \#4 (https://www.thingiverse.com/thing:1264619.)

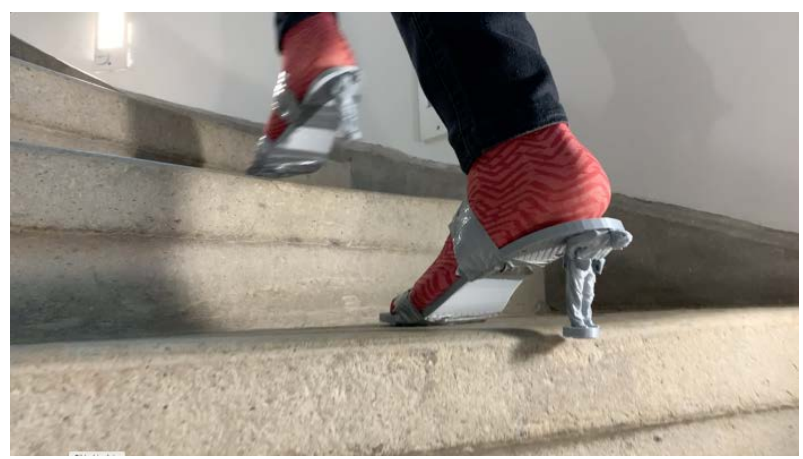

Figure 4: Performance with 3D-Model Peter Weibel and I \#11, Museum K21 in Düsseldorf. Photo: Nils Kemmerling.

In this context, and based on openly accessible data from several institutions, taken from the 3D data exchange platform Thingiverse, I have created 
modifications and remixes of a 3D scan by Peter Weibel (Director of the ZKM-Center for Art and Media Karlsruhe). I have also made some of these remixes available as free downloads on the 3D platform, and used 3D printed models for different interventions such as a walk through various museum staircases, video performances (see Figure 4 above); photographs, renderings, objects, texts, and also interactions and surveys (https://www.thingiverse.com/search?q=xpistin\&dw $\underline{\mathrm{h}=755 \mathrm{e} 19 \mathrm{ad} 18571 \mathrm{fb})}$.

An interconnected, shared observation or study that is characterised by the conscious, collaborative efforts of different observers from different disciplines, might be able to merge their different perceptions and consequently produce new knowledge. For instance, in early modern Europe, collective empiricism in the field of natural science saw anatomists joining forces with artists, and their competing ways of seeing and showing collided. Despite differing and hierarchical modes of thinking, this delivered exciting results. This justified the vision of collective net-empiricism. Even at that time, by experimenting in the field of natural science, they had been dealing with different models of collective authorship.

Following this discussion, we may consider that the generating these objects is a creative process that marks the new status of the resulting object, as a new object, and, consequently, as an absolute reproduction, which is related to the original object through its difference. It is a model that has a location-independent physical presence and contains duplications of the reproduction.

\section{SPECULATIVE MODEL}

Furthermore, these models are theoretical or objective abstractions, which serve to interpret a phenomenon or object, allowing us to draw conclusions about the phenomenon and thus facilitate access to them or give access to them in the first place. They have an explanatory quality, which comprehensibly explains inaccessible aspects of the phenomenon and can establish a link to the original. In addition to that, the models also have a visualizing property, realised by viewing that can make predictions and is therefore able to add more information about the content they represent. On the one hand, models facilitate access to content and make it better understandable, on the other hand, they function selectively and only reflect aspects of an original (Vögtli \& Ernst 2007, pp.42-57).

The openly accessible online 3D-object brings different users together, encourage them to communicate, to discuss ideas in order to develop common tasks together. It acts as a model, as a prototype, as is common in design research, for a later product. The design can be tested multidirectionally on a community platform, flashed out with different approaches and, in a next step, brought to a solution. In that way, this 3D-object, as an incomplete product, as a permanent prototype, can be incorporated and tested in a variety of scenarios. Model does not only refer to a material artefact, but it can also be an idea or an intervention on the platform. Furthermore, a specific framing can be defined, which can be observed and experienced. Similar to how a perpetual beta works, the 3D-object does not leave its prototypical model character. It exists on the community platform as an informal fragment, which can only be realised under certain framework conditions and not solely through a first realisation.

Designing and developing always manifests itself through models; these can be material or immaterial, such as sketches, drawings, quick prototypes, working models, imaginations, images, texts, models of thought, etc., and they can play an important role in the unfolding of scientific and technological creativity. Models as demonstrations of a thought process can be realised in different media. They can initiate thought processes, but also steer them, provide implicit insights and be acted on scientifically. However, they were not always considered in that manner. Until the second half of the $19^{\text {th }}$ century, with only a few exceptions in the scientific context and with the exception of mathematical formulas, hardly any other means of illustration other than e.g. sketches from notebooks of scientists were recognised.

Today there is a general consensus that informal notes, schematic thought experiments and fragments act in the way that is true for Andreas Töpfer's drawings in the book Speculative Drawing from 2014 on Armen Avanessian's presented theories. The speculative drawings are models that provoke thinking, both in pictures and in theoretical concepts - between science and practical experience. They do not serve as an illustration or a visual shortcut of the theory, but they must be read for their own sake. According to Avanessian, "[...] the drawings are not to be read as meaningful, individual images but as a (syntactically structured) series, in which a seeing knowledge develops - a knowledge closed to (or enclosed in) the texts. That's why these speculative drawings need to be read" (Avanessian 2014, p.19). He understands the drawings not only as extensions of the texts, but also as theoretical productions. Here, the drawings do not appear as reproductions of the theory, and if they appear as such, they behave mimetically, which allows them to realise the reproduction in such a way that a new idea or form is produced (ibid., p.23). Avanessian does not understand the 
drawing as competing with the text; the drawings are not directed against the semantics of the text, but are rather intermedia and recursive translations of thought models: "[...] from language into drawing into language and so on [...]" (ibid., p. 25).

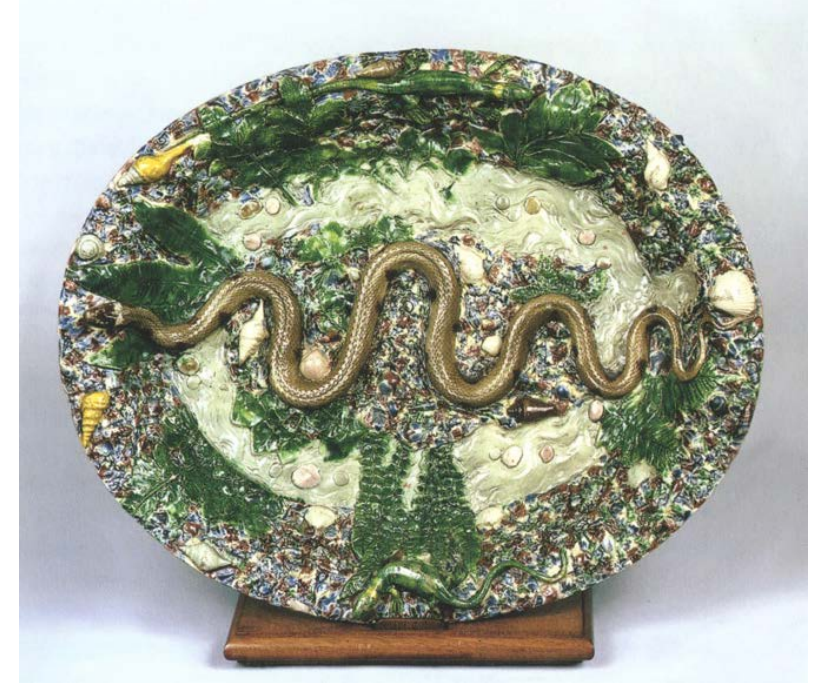

Figure 5: Bernard Palissy, Bowl with the natural cast of a snake and other animals, Wallace Collection, London $16^{\text {th }}$ century.

Just like the drawings by Andreas Töpfer, that appear mutually reinforcing with the support of theories, also haptic objects can induce similar processes and can be understood as speculative objects. Examples from the field of ceramics are the bowls by the French ceramist Bernard Palissy from the $16^{\text {th }}$ century (see Figure 5). On his ceramics, he used natural casts, mainly from molluscs, which he glazed in bright colours. The exceptional feature in this case was not only the great craftsmanship or the pronounced naturalism of his ceramics in the sense of microcosmic reflections of nature. Palissy was not only a potter, but also a natural scientist and author of two dialogue collections on the sciences of the earth. He combined practical research and theory; used his acquired knowledge from his craft to refute complicated metaphysical or philosophical theses and made the significance of linking practical knowledge and empirical methods in philosophical thinking explicit (Kemp 2003, p.33).

Another example, also from ceramic art, are the vessels of American potter Joan Lederman (see Figure 6). She uses special materials for her glazes, e.g. soil samples from paleoclimate research sediments, thereby creating links between space and time. During the firing process, particles of the sediment composition unfold in a surprising way, allowing new room for interpretation. The experimental handling of the kiln as an instrument of knowledge comes to the fore here, providing information for analysis and offering new practical fields of perceptual research (ibid., p.205).

My artistic work, the citation generator Quotemodulator, is to be positioned in this field of tension between discovery and knowledge as well as in the context of speculative models. It is a programmed generative tool that enables the transformation of scientific quotations into 3D objects. Parameters are defined from a linguistic point of view and, based on a geometric basic body, an abstract 3D printable form can be generated. This opens up new fields of interpretation and allows statements to be compared and assessed in regard to formal aesthetics. The text description, structure and analysis can be made accessible by the haptic object.

Literary terms, such as quotations, point to relationships between different texts, to intertextuality, which are explicitly evoked by this work. The quotations enter into a dialogue with each other, parody and question one another. The resulting three-dimensional citation objects behave metatextually and can be understood as comments in a discussion that takes place both in regard to content and form.

According to Avanessian: "Like thinking that is communicated by words, these theory-drawings produce sense in a complex syntactic correlation. It is only in the original sense of both the Greek theorein (to watch, to view) and the Latin speculari (to observe)" (Avanessian 2014, p.21).

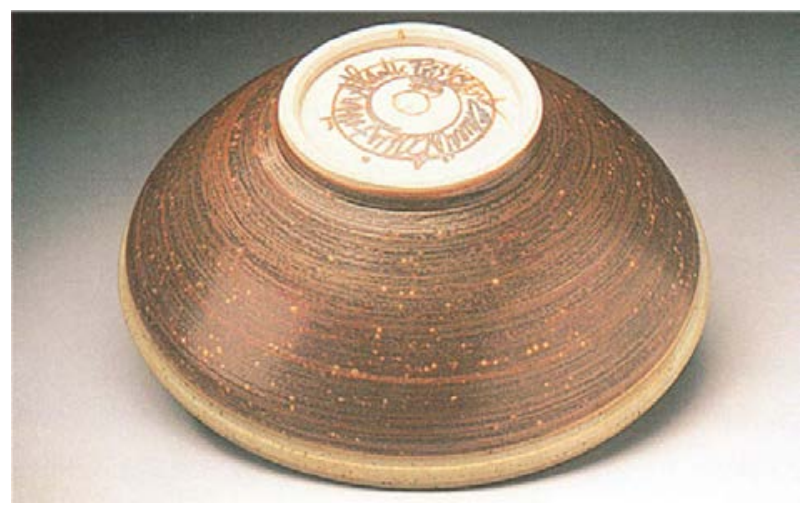

Figure 6: Joan Lederman, North Atlantic Deep Sea Bowl, glazed with sediment from soil samples from the bottom of the North Atlantic, 1996 (Kemp 2003, p.207).

The work Quotemodulator (see Figures 7 and 8) is linked to Peirce's thought process and the embodiment of thinking in diagrams or graphs. In contrast to art pictures, which can show a degree of autonomy, diagrams are fundamentally anchored in the text and cannot be explained without context. They are hybrids, consisting of graphic elements and text, which are deeply embedded in predefined 
realities. Depending on the objective of the diagram, different types can be created.

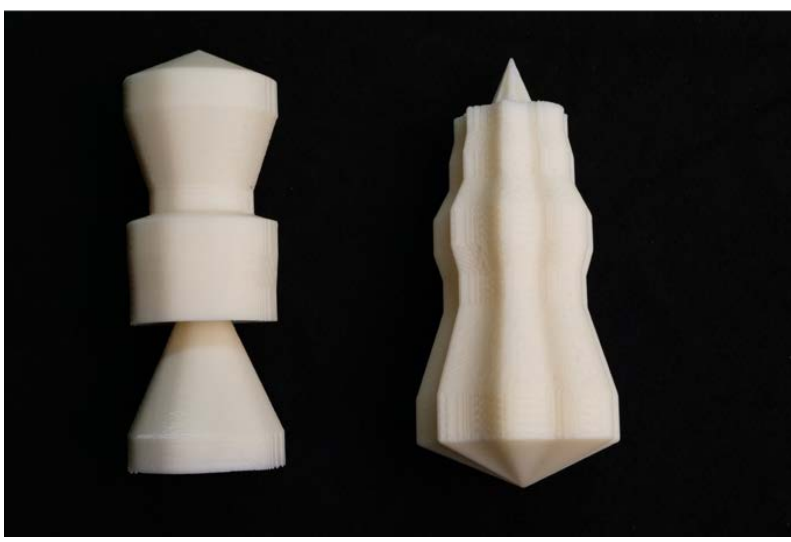

Figure 7: Quotemodulator, two citation objects $3 D$ printed in ABS plastic in comparison. Photo: Laura Oldörp.

Right: "With every good craftsman, practical action and thinking are in constant dialogue. Through this dialogue, permanent habits develop, and these habits lead to a constant change between solving and finding problems" (Sennett 2009, p.20).

Left: "Almost every action by the worker should be preceded by one or more preparatory actions by management that enable the worker to do his job better and faster than he could do it alone" (Taylor 1913, p.26).

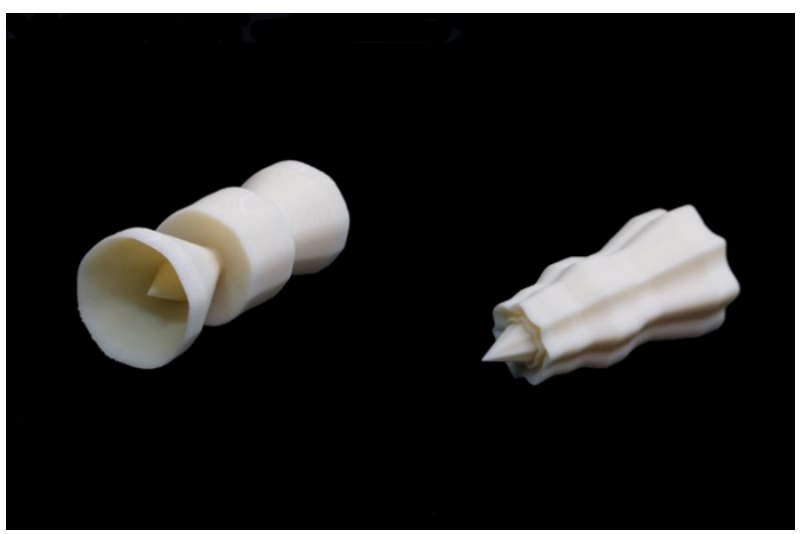

Figure 8: Quotemodulator. Two citation objects 3D printed in ABS plastic in comparison. Photo: Laura Oldörp.

A three-dimensional object generated by the Quotemodulator can be understood as a threedimensional diagram of cohesion that makes predefined parameters and their relationships visible to one another. It is a three-dimensional model with diagrammatic aspects that can be analysed haptically.

\section{According to Avanessian:}

"Like thinking that is communicated by words, these theory-drawings produce sense in a complex syntactic correlation. It is only in the original sense of both the Greek theorein (to watch, to view) and the Latin speculari (to observe)" (Avanessian 2014, p.21).

In the sense of Sybille, humans have access to different modalities of representation. "We not only have the auditory, time-sequenced linguistic articulation, but also a visual, spatially organised form of graphical articulation" (Krämer 2016, p.70, own translation). The spatial-haptic articulation, which is a kinesthetic perception, can also be added here. The human tactile spatial resolution has the ability to distinguish subtle spatial or multidimensional details, so that something can be added to their interpretation by a tactile comparison of different citation results.

Like a diagram, the Quotemodulator should be understood as an apparatus "[...] in order to homogenise heterogeneous things in such a way that something different can be compared." (ibid., p.71, own translation). This is how relations between differing things are created and connections between objects and text, looking and recognizing, are formed. Based on other parameters, tokens and types have been implemented in the text analysis of the Quotemodulator. In quantitative linguistics and quantitative stylistics, the type-token relation plays a major role, since it serves the characterisation of texts in regard to its richness in vocabulary. The conceptual pair token-type was introduced by Charles S. Peirce in 1906:

A common mode of estimating the amount of matter in a MS. or printed book is to count the number of words. There will ordinarily be about twenty thes on a page, and of course they count as twenty words. In another sense of the word "word," however, there is but one word "the" in the English language; and it is impossible that this word should lie visibly on a page or be heard in any voice, for the reason that it is not a Single thing or Single event. It does not exist; it only determines things that do exist. Such a definitely significant Form, I propose to term a Type. A Single event which happens once and whose identity is limited to that one happening or a Single object or thing which is in some single place at any one instant of time, such event or thing being significant only as occurring just when and where it does, such as this or that word on a single line of a single page of a single copy of a book, I will venture to call a Token, An indefinite significant character such as a tone of voice can neither be called a Type nor a Token. I propose to call such a Sign a Tone. In order that a Type may be used, it has to be embodied in a Token which shall be a sign of the Type, and thereby of the object the Type signifies. I propose to call such a Token of a Type an Instance of the Type (Peirce 1906, p.505).

In the field of symbolic signs, the relationship between embodiment and physical reality, between 
secondness and thirdness, is reflected in the relation of tokens and types. In his category theory, Peirce describes the potential quality of the sign as firstness (tone), as secondness (token) - every individual sign, while thirdness (type) for him represents the rule that determines a potentially infinite creation of tokens (Engel 2012, p.46). The citation objects are physically embodied relations of Peirce's thirdness. Their reception is open, varied and always depends on the interpretant.

Furthermore, three-dimensionality can be represented as a model of comprehension in this work. According to Vilém Flusser, numbers are unambiguous and, in contrast to letters, precise in their meaning because they are clearly separated from each other by an interval. The numerical code is tangible and differs from the language code in as far as it is clear and distinct, while the latter is flexible, ambiguous and therefore not suitable for formulating cognitive models. From the $15^{\text {th }}$ century onwards, it has been recognised that exact knowledge is quantifying and inexact knowledge, in contrast, qualifying. With this effort I would like to blur the separation. In the Quotemodulator, the text is translated into numerical code so that it can then be physically realised as a three-dimensional object. As a result, it is abstracted first to allow comprehension. These objects are numerically generated synthetic realisations that already contain the criticism.

Another example of the Quotemodulator is the work in which vase forms are generated using philosophical or scientific texts of comparable content. The comparison of the authors' theses is achieved here via containers. Texts by various authors on spaces were examined. Thereby, Marchall McLuhan's ideas of spaces exist next to Georges Perece's or opposite Gaston Bachelard's as physical objects in the real space (see Figure 9). The vases can be used to discuss differences and similarities.

In Peirce's sense, his drawings are a central aspect of his philosophy. He operates in a scientific context using aesthetic processes and establishes artistic forms of knowledge as scientific practices. He displays a thinking in pictures, which can also be transferred to thinking in objects. Objects or everyday items as material embodiments of thinking processes can influence perspectives of thinking and remove disciplinary boundaries. Aesthetic processes and artistic practices, such as 3D modelling, can operate scientifically and provide important fundamental principles for a debate about visual thinking.

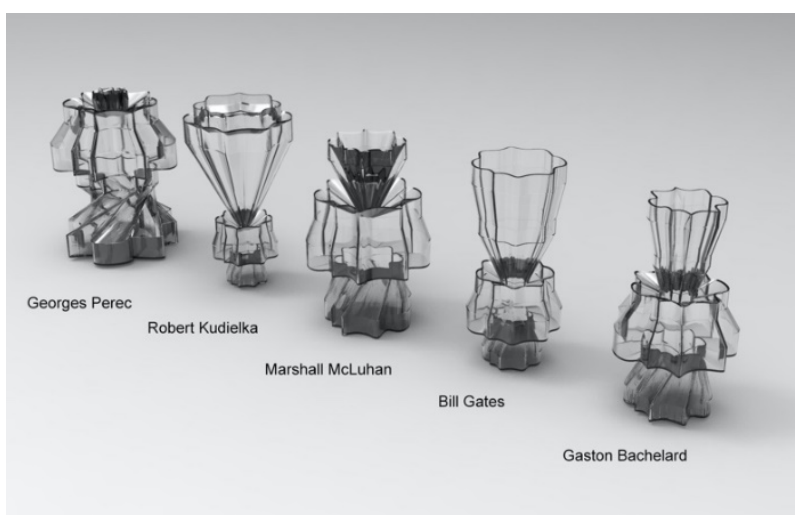

Figure 9: Quotemodulator, genetated $3 D$ vase forms. Rendering: Christina Karababa.

\section{REFERENCES}

Avanessian, A. and Töpfer. (2014) Spekulative Drawing: 2011-2014, Sternberg Press, Berlin.

Engel, F., Queisner, M. and Viola, T. (eds) (2012) Das Bildnerische Denken: Charles S. Peirce, Akademie Verlag $\mathrm{GmbH}$, Berlin.

Frank, G. and Lange, B. (2010) Einführung in der Bildwissenschaft,- Bilder in der visuellen Kultur, BWG (Wissenschaftliche Buchgesellschaft), Darmstadt.

Kemp, M. (2003) Bilderwissen, die Anschaulichkeit naturwissenschaftlicher Phänomene, Literatur und Kunst Verlag, Köln.

Krämer, S. (2016) Figuration, Anschauung, Erkenntnis: Grundlinien einer Diagrammatologie, Suhrkamp Verlag, Berlin.

Peirce, C. S. (1906) Prolegomena to an Apology for Pragmaticism, Monist, 16. http://campus.unibo. it/270857/113/\%5BPeirce\%201906\%5D\%20Proleg omena.pdf (retrieved 20 April 2018).

Sennett, R. (2009) Handwerk, BvT Berliner Taschenbuch Verlag, Berlin.

Taylor, F. W. (1913) Die Grundsätze wissenschaftlicher Betriebsführung (The Principles of Scientific Managment), R. Oldenburg Verlag, München and Berlin.

Vögtli, A. and Ernst, B. (2007) Wissenschaftliche Bilder-Eine Kritische Betrachtung, Schwabe AG Verlag Basel. 